\title{
A Survey on the Use of the Internet of Multimedia Things for Precision Agriculture and the Agrifood Sector ${ }^{\dagger}$
}

\author{
Alvertos Ioannis Mourikis *, Romanos Kalamatianos, Ioannis Karydis (D) and Markos Avlonitis \\ Department of Informatics, Ionian University, 49132 Corfu, Greece; rkalam@ionio.gr (R.K.); \\ karydis@ionio.gr (I.K.); avlon@ionio.gr (M.A.) \\ * Correspondence: c20mour@ionio.gr; Tel.: +30-2661-087-264 \\ + Presented at the 13th EFITA International Conference, online, 25-26 May 2021.
}

check for updates

Citation: Mourikis, A.I.;

Kalamatianos, R.; Karydis, I.;

Avlonitis, M. A Survey on the Use of the Internet of Multimedia Things for Precision Agriculture and the Agrifood Sector. Eng. Proc. 2021, 9, 32 https://doi.org/10.3390/engproc 2021009032

Academic Editors: Dimitrios Aidonis and Aristotelis Christos Tagarakis

Published: 3 December 2021

Publisher's Note: MDPI stays neutral with regard to jurisdictional claims in published maps and institutional affiliations.

Copyright: (c) 2021 by the authors. Licensee MDPI, Basel, Switzerland. This article is an open access article distributed under the terms and conditions of the Creative Commons Attribution (CC BY) license (https:// creativecommons.org/licenses/by/ $4.0 /)$.

\begin{abstract}
The Internet of Things (IoT) has already penetrated an ever-increasing array of daily aspects of life. IoTs bridge the analog and digital worlds in an unprecedented manner and degree by providing in situ sensing. Adding to the IoT the capability to collect interrelated multi-modal sensing, the use of the Internet of Multimedia Things (IoMTs) has recently been exhibited to significantly enhance the role of Information and Communication Technologies (ICT) in numerous applications, and most importantly in agrifood systems. In this work, we review key recent works in the conjunction of the three domains of IoMT, agrifood and precision agriculture and present open research directions.
\end{abstract}

Keywords: Internet of Multimedia Things; precision agriculture; agrifood sector; open research directions

\section{Introduction}

A combination of a plethora of factors, including (but not limited to) the man-made climate change crisis [1,2], the world's positive population growth, the ever-increasing penetration and ubiquitousness of ICT in almost all aspects of life, as well as the requirement for qualitative and quantitative nutrition of contemporary humans, all lend themselves to the amalgamation of contributing domains of precision agriculture/farming in agrifood systems. Agrifood systems, in their broadest sense, refer to crops, livestock, forestry, fisheries, and aquaculture [3], among domains producing food. Given this wide breadth of agrifood systems' contribution to food, their importance to humans cannot be overstated. Nevertheless, these systems are under strain and their sustainability is a multi-faceted challenge [4-6].

The ICTs for the collection of information and knowledge mining as well as the customised application of methods in the field, with, among other technologies, artificial intelligence, drones, and the various versions of Internet of Things (IoT) have been dubbed the latest, digital, (r)evolution of agriculture [7-10]. The central tenet of this evolution is the application of the appropriate method to the proper location at the right time and of the suitable intensity, i.e., the notion of precision farming [11]. Accordingly, in this work, we are motivated by the recent developments in ICT to address existing and new challenges of the agrifood domain. This work's contribution is in collecting, processing, homogenizing, and drawing a "bird's-eye view" presentation from research in multimedia IoT (IoMT), agrifood, and precision farming/cultivation, as well as their intersection. The rest of the work is organized as follows: Section 2 presents definitions and working examples of the three domains of IoMT, agrifood, and precision farming that act as pillars to our work. At the same time, Section 2 presents some of the key influential and recent works for each of the three domains of IoMT, agrifood, and precision agriculture, both as distinct directions as well as in conjunction. The work is concluded in Section 3, where open research directions that future research on the domain may draw upon are detailed. 


\section{Definitions and Working Examples}

\subsection{Agrifood}

Agriculture has had a fair share of evolutionary periods the last approximately 10,000 years, each of which had, in turn, a profound effect on humanity $[7,10,12]$ : the first agrarian revolution, approx. 10,000 BC, was driven by the transition from nomadic life to settlements, and thus organised agriculture with the aid and efficiency of tools such as ploughs; the second (17th-19th centuries) originated the practice of crop rotation, the initiation of technical methodologies to support human labour, as well as the reordering of farmland management the third (approx. 1910-2000) stemmed from extended use of complex mechanisation, the industrialisation of farming, as well as the use of fertilisation and genetic engineering on crops. These changes (key, among several others) allowed the evolution of the population from approx. 4 million in $8000 \mathrm{BC}$ to 400 million in 1700s [13] to 6.1 billion in 2000 .

Most of these advancements had a significant effect on more than crops' cultivation, reaching domains such as livestock, forestry, fisheries, aquaculture, etc. Thus, the term agriculture, in the context of this work, and as per the common definition "the science, art, or practice of cultivating the soil, producing crops, and raising livestock and in varying degrees the preparation and marketing of the resulting products" [14], is utilised in a broad manner, with focus on the production of nutritional outputs for humans from flora and fauna, thus resulting in the term "agrifood". Agrifood systems address the needs of a very significant part of humans' nutrition, which is colloquially referred to as "food from farm to fork" and the effects of unsuccessful such systems have grave consequences leading to "resources' pressure and human suffering" [3].

\subsection{Internet of (Multimedia) Things}

The group of technologies within the Internet of Things (IoT) categorisation provide an intermediary between the physical and virtual worlds and a layer of interconnected, distributed and in situ sensing and processing of information [15]. Under the umbrella of IoT, a wide diversity of variations as to the "thing"'s capabilities, characteristics and scenarios of application have been proposed [16]. Herein, we focus on the variety of IoTs that enhance common IoT sensors, focusing solely on scalar measurements, found in most agrifood scenarios by providing both scalar and interrelated multi-modal information, based on which a wealth of more advanced agrifood decision scenarios can successfully be met, i.e., the Internet of Multimedia Things (IoMT). IoMTs offer unique advantages in the digitisation of agrifood processes in all aspects of the "from cultivator to consumer" chain.

Visual stimuli information, such as images and/or videos, has been shown to have a wide breadth of applications in agriculture, especially when used in conjunction with computer vision methods [17]: identification of cultivation's products as per size, shape, colour, holistic condition and potential output/yield [18], over-accumulation or deficiency of nutrients [19], invasive species and pests [20], as well as estimation of developmental parameters of the cultivation. Similarly, auditory cue sensors are more common than expected in various sensor sets used in agriculture [21] for purposes such as invasive species and pest identification [22], rainfall estimation [23], soil characteristic evaluation [24], volume measurement of agricultural products [25], and many more.

Moreover, IoMTs can support ICT services that will promote high-quality products by: (a) providing consumers with details about each product and producer (origin, certifications, farming practices, milling and packaging details, historical facts, producer's page, contextual information, review from other consumers, etc.); (b) providing producers with suggestions and support from experts to improve the quality of their products and to be guided through a sustainable cultivation process (reducing water and pesticide usage, having access to local meteorological information, etc.); (c) providing consumers with specific information (understandable scientific details about each product, nutraceutical analysis, etc.) and suggestions from experts; and (d) creating a social-level web of interactions where all interested parties can comment, review, interact and state their opinion 
about the products, generating a culture of informed consumption, digital promotion and a "crowd-based acceptance certification".

\subsection{Precision Farming}

Precision (or smart) agriculture/farming/cultivation (or "Agriculture 4.0"), in this context almost all synonymous, has been dubbed the fourth agrarian (r)evolution. A healthy discussion as to this (r)evolution's necessity and its envisaged positive and/or negative consequences is already underway [26]. One of the most dramatic results of this evolution is expected through the integration of all stakeholders of agrifood, even at the conceptual level, thanks to the ICT advancements, as described in Section 2.2.

Artificial intelligence represents a pillar of precision farming [27] in order to achieve processes oriented at soil sciences and soil-specific cultivation management, the management of geoinformation, calculation of fertilisation rate, customisation of cultivation solutions based on site-specific characteristics and the use/definition of cultivation management zones, extended use of high-precision location information of assets and cultivation, yield mapping, methods for variable rate of herbicides/pesticides, high specificity adaptable irrigation rate, near real-time remote, high precision and various sensing measurements, automatic cultivation asset navigation and work-load mechanisation through drones/robotics, and proximal sensing of cultivation and its environment [11].

\section{Conclusions}

The fourth agrarian (r)evolution is upon us, and a number of interesting open research directions exist: the philosophical and ethical quandaries posed by extensive dependencies on technological advancements and AI; the inclusivity of precision agriculture's methods to all stakeholders (from policy-makers, to producers, to consumers); the mitigation strategies for the unexpected and/or unwanted (side-)effects of the evolution; the balancing of the role of technological innovations vs. innovations in information analysis and decision support in the evolution; the environmental parameters of the evolution (e.g., the footprint of the life-cycle of all parts of the evolution), and many others. As with all new and exciting ventures, the fourth agrarian (r)evolution needs to evolve to its best self in order to reap the benefits and address in the best possible way the nutrition of humankind.

Author Contributions: All authors have contributed equally to the processes of conceptualisation, methodology, validation, investigation, resources, writing-original draft preparation and review and editing. All authors have read and agreed to the published version of the manuscript.

Funding: This research received no external funding.

Acknowledgments: The financial support of the European Union and Greece (Partnership Agreement for the Development Framework 2014-2020) under the Regional Operational Programme Ionian Islands 2014-2020, for the project "Olive Observer" is gratefully acknowledged.

Conflicts of Interest: The authors declare no conflict of interest. The funders had no role in the design of the study; in the collection, analyses, or interpretation of data; in the writing of the manuscript, or in the decision to publish the results.

\section{References}

1. Figueres, C.; Rivett-Carnac, T. The Future We Choose: Surviving the Climate Crisis; Vintage: New York, NY, USA, 2020.

2. Crist, E. Beyond the Climate Crisis: A Critique of Climate Change Discourse. Telos 2007, 141, 29-55.

3. Herrero, M.; Jones, P.; Thornton, P.; Chen, M.; Gerland, P.; Gilbert, M. Chapter 33-Agrifood Systems. In Sustainable Food and Agriculture; Campanhola, C., Pandey, S., Eds.; Academic Press: Cambridge, MA, USA, 2019; pp. 305-330. [CrossRef]

4. Barrett, H.; Rose, D.C. Perceptions of the Fourth Agricultural Revolution: What's In, What's Out, and What Consequences are Anticipated? Sociol. Rural. 2021. [CrossRef]

5. Devaux, A.; Goffart, J.-P.; Kromann, P.; Andrade-Piedra, J.; Polar, V.; Hareau, G. The Potato of the Future: Opportunities and Challenges in Sustainable Agri-food Systems. Potato Res. 2021. [CrossRef]

6. El Bilali, H.; Strassner, C.; Ben Hassen, T. Sustainable Agri-Food Systems: Environment, Economy, Society, and Polic. Sustainability 2021, 13, 6260. [CrossRef] 
7. Lombardo, S.; Sarri, D.; Corvo, L.; Vieri, M. Approaching to the Fourth Agricultural Revolution: Analysis of Needs for the Profitable Introduction of Smart Farming in Rural Areas. HAICTA 2017. pp. 521-532. Available online: https://flore.unifi.it/ retrieve/handle/2158/1112565/296930/360.pdf (accessed on 22 April 2021).

8. Zhai, Z.; Martínez, J.F.; Beltran, V.; Martínez, N.L. Decision support systems for agriculture 4.0: Survey and challenges. Comput. Electron. Agric. 2020, 170, 105256. [CrossRef]

9. De Clercq, M.; Vats, A.; Biel, A. Agriculture 4.0: The Future of Farming Technology. 2018; pp. 11-13. Available online: https:/ / skyfarms.io/wp-content/uploads/2020/08/84-OliverWyman-World-Government-Report-Agriculture-4.0.pdf (accessed on 22 April 2021).

10. Rose, D.C.; Chilvers, J. Agriculture 4.0: Broadening Responsible Innovation in an Era of Smart Farming. Front. Sustain. Food Syst. 2018. Available online: https:/ / doi.org/10.3389/fsufs.2018.00087 (accessed on 23 April 2021). [CrossRef]

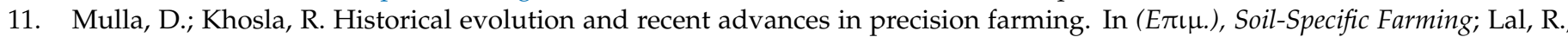
Stewart, B., Eds.; Taylor Francis: Abingdon, UK, 2016; pp. 1-35. Available online: https:/ / doi.org/10.1201/b18759 (accessed on 23 April 2021).

12. Faris, J.D. Wheat Domestication: Key to Agricultural Revolutions Past and Future. In Genomics of Plant Genetic Resources: Volume 1. Managing, Sequencing and Mining Genetic Resources; Springer: Dordrecht, The Netherlands, 2014; pp. 439-464. [CrossRef]

13. Lal, R.; Reicosky, D.; Hanson, J.D. Evolution of the plow over 10,000 years and the rationale for no-till farming. Soil Tillage Res. 2007, 93, 1-12. [CrossRef]

14. Merriam-Webster. Agriculture. Retrieved from Dictionary by Merriam-Webster. 25 July 2021. Available online: https://www. merriam-webster.com/dictionary/agriculture (accessed on 19 April 2021).

15. Kopetz, H. Internet of things. In Real-Time Systems; Springer: Boston, MA, USA, 2011; pp. 307-323.

16. Kassab, W.; Darabkh, K.A. A-Z survey of Internet of Things: Architectures, protocols, applications, recent advances, future directions and recommendations. J. Netw. Comput. Appl. 2020, 163, 102663. [CrossRef]

17. Patrício, D.I.; Rieder, R. Computer vision and artificial intelligence in precision agriculture for grain crops: A systematic review. Comput. Electron. Agric. 2018, 153, 69-81. [CrossRef]

18. Mazloumzadeh, S.; Shamsi, M.; Nezamabadi-pour, H. Fuzzy logic to classify date palm trees based on some physical properties related to precision agriculture. Precis. Agric. 2010, 11, 258-273. [CrossRef]

19. Wei, F.; Yan, Z.; Tian, Y.; Cao, W.; Xia, Y.; Li, Y. Monitoring leaf nitrogen accumulation in wheat with hyper-spectral remote sensing. Acta Ecol. Sin. 2008, 28, 23-32. [CrossRef]

20. Kalamatianos, R.; Karydis, I.; Doukakis, D.; Avlonitis, M. DIRT: The Dacus Image Recognition Toolkit. J. Imaging 2018, 4, 129. [CrossRef]

21. Shafi, U.; Mumtaz, R.; García-Nieto, J.; Hassan, S.A.; Zaidi, S.; Iqbal, N. Precision Agriculture Techniques and Practices: From Considerations to Applications. Sensors 2019, 19, 3796. [CrossRef] [PubMed]

22. Potamitis, I.; Rigakis, I.; Fysarakis, K. Insect Biometrics: Optoacoustic Signal Processing and Its Applications to Remote Monitoring of McPhail Type Traps. PLoS ONE 2015, 10, e0140474. [CrossRef] [PubMed]

23. Avanzato, R.; Beritelli, F. An Innovative Acoustic Rain Gauge Based on Convolutional Neural Networks. Information 2020, 11, 183. [CrossRef]

24. Rillig, M.C.; Bonneval, K.; Lehmann, J. Sounds of Soil: A New World of Interactions under Our Feet? Soil Syst. 2019,3 , 45. [CrossRef]

25. Nishizu, T.; Ikeda, Y. Volume Measuring System by Acoustic Method for Agricultural Products, 1: Precision and Accuracy of Volume Measuring System by Applying Helmholtz Resonance Phenomena. J. Jpn. Soc. Agric. Mach. 1995, 57, 47-54. Available online: https: / /agris.fao.org/agris-search/search.do?recordID=JP9603020 (accessed on 15 April 2021).

26. Barrett, C.B.; Benton, T.G.; Cooper, K.A.; Fanzo, J.; Gandhi, R.; Herrero, M.; James, S.; Kahn, M.; Mason-D’Croz, D.; Mathys, A.; et al. Bundling innovations to transform agri-food systems. Nat. Sustain. 2020, 3, 974-976. [CrossRef]

27. Khanna, A.; Kaur, S. Evolution of Internet of Things (IoT) and its significant impact in the field of Precision Agriculture. Comput. Electron. Agric. 2019, 157, 218-231. [CrossRef] 